\title{
Applications of Raman micro-spectroscopy to stem cell technology: label-free molecular discrimination and monitoring cell differentiation
}

\author{
Adrian Ghita ${ }^{1}$, Flavius C Pascut ${ }^{1}$, Virginie Sottile ${ }^{2}$, Chris Denning ${ }^{2}$ and loan Notingher ${ }^{1 *}$
}

\author{
* Correspondence: \\ ioan.notingher@nottingham.ac.uk \\ ${ }^{1}$ School of Physics and Astronomy, \\ University of Nottingham, \\ Nottingham NG7 2RD, UK \\ Full list of author information is \\ available at the end of the article
}

\begin{abstract}
Stem cell therapy is widely acknowledged as a key medical technology of the 21st century which may provide treatments for many currently incurable diseases. These cells have an enormous potential for cell replacement therapies to cure diseases such as Parkinson's disease, diabetes and cardiovascular disorders, as well as in tissue engineering as a reliable cell source for providing grafts to replace and repair diseased tissues. Nevertheless, the progress in this field has been difficult in part because of lack of techniques that can measure non-invasively the molecular properties of cells. Such repeated measurements can be used to evaluate the culture conditions during differentiation, cell quality and phenotype heterogeneity of stem cell progeny. Raman spectroscopy is an optical technique based on inelastic scattering of laser photons by molecular vibrations of cellular molecules and can be used to provide chemical fingerprints of cells or organelles without fixation, lysis or use of labels and other contrast enhancing chemicals. Because differentiated cells are specialized to perform specific functions, these cells produce specific biochemicals that can be detected by Raman micro-spectroscopy. This mini-review paper describes applications of Raman micro-scpectroscopy to measure moleculare properties of stem cells during differentiation in-vitro. The paper focuses on time- and spatially-resolved Raman spectral measurements that allow repeated investigation of live stem cells in-vitro.
\end{abstract}

\section{Springer}

\section{Introduction}

Tissue engineering and stem cells technology

The capacity of the human body to recover from injuries or diseases is limited and in some situations almost non-existent. The standard medical procedures, which involve surgery and drug based-therapies, have shown limitations in treating many complex conditions. New alternatives to existing medical treatments are required as the incidence of the medical conditions with clinical impact on society in terms of mortality, morbidity and quality of life is continuously increasing. Tissue engineering is an emerging field in modern medicine that aims to grow tissue in laboratories that can be used for replacement of diseased tissue and organs, repair and regeneration. Tissue replacement involves the growth of tissue and organs in-vitro that can be implanted in the human body [1]. The repair involves medical treatment at the biological and molecular level. The main advantages of these approaches are related to an increased availability

(c) 2015 Ghita et al.; licensee Springer on behalf of EPJ. This is an Open Access article distributed under the terms of the Creative Commons Attribution License (http://creativecommons.org/licenses/by/4.0), which permits unrestricted use, distribution, and reproduction in any medium, provided the original work is properly credited. 
of grafts and reducing the risks associated with viral infections (e.g. tissue rejection) or negative immunological response [2].

A number of different sources of cells are considered for tissue engineering and regenerative medicine. Mature fully differentiated somatic cells, adult and embryonic stem cells have been used in different applications. The somatic cells extracted from the patients have no risks associated with the integration and immune response, but these cells can be obtained in limited numbers and have low proliferation rates. Adult stem cells are immature undifferentiated cells extracted from the human body, usually bone marrow, and are capable of generating daughter cells. The self-renewal process occurs over the entire lifetime of the biological host. However, the limited number of available adult stem cells in the human body gives rise to impediments in the self-healing capabilities of the human body. Embryonic stem cells (ESCs) are derived from the inner cell mass of mammalian blastocyst and can differentiate spontaneously in-vitro giving rise to pluripotent cells [3]. ESCs can serve as a potential research model for tissue development, cancer formation and metastasis, phenotype commitment, stem cells based therapy, gene therapy strategies and drug design [4]. Despite their clinical potential, the progress of stem cell therapy has been slow, mainly due to issues related to cell quality, phenotype heterogeneity, delivery, integration, proliferation and differentiation inside the host [5].

\section{Review}

Raman Micro-Spectroscopy (RMS)

During the last century, a plethora of chemical and imaging techniques have been developed to understand the molecular dynamics underpinning the fundamental cellular processes such as proliferation, differentiation or apoptosis [6,7]. Each of these techniques can address certain applications or particular biological problems or processes. Optical microscopy techniques are particularly attractive due to their ability to provide information with high-spatial resolution while using compact and cost-effective instrumentation. Nevertheless, conventional microscopy relies on refractive-index contrast in a sample and does not provide molecular information. Fluorescence microscopy relies on selective imaging of cellular molecules labelled with specific fluorescent dyes $[8,9]$. Thus, its capabilities are affected by limited stability and photo bleaching of the fluorophores, while the free radical released inside the cells during photo-excitation can induce toxicity. Certain fluorescence labels may influence biochemical processes in cells or cannot enter live cells to access cytoplasmic molecules (often fluorescence imaging requires fixation of the cells).

The Raman effect is based on inelastic scattering of photons when electromagnetic waves interact with molecules. As a consequence of the energy transfer between the vibrating molecules in the sample and the electromagnetic waves, the Raman scattered photons have different frequencies compared to the incident photons, frequencies that are related to the vibrational levels of the molecules. Thus, Raman spectroscopy is a label-free analytical technique and molecular information can be obtained in a nondestructive way with no sample preparation: light is used for excitation of the molecules and the inelastically scattered light is detected for molecular analysis. Raman spectroscopy has been extensively used for molecular analysis of biological tissues and disease diagnostic [10-13]. 
An important advantage of RMS is that the information regarding molecular vibrations can be obtained using microscopy instrumentation operating in the visible and near-infrared spectral regions. RMS has benefited enormously from the recent advances in high-power laser technology, optical microscopy, fibre optics and detectors with high quantum efficiency in this spectral range. Another important advantage of Raman micro-spectroscopy for live cell imaging is that the background Raman signals from water are significantly weaker compared to signals obtained from cell's molecules. Therefore, RMS can be used to measure repeatedly the molecular properties of live cells maintained in culture media.

\section{Label-free Raman spectral imaging of cells}

The first Raman micro-spectrometer was demonstrated by Dhamelincourt and Delhaye in 1973 [14] but it was not until 1990 when Puppels et al. reported the first Raman spectra of individual cells [15]. Since then, Raman spectroscopy has been extensively used for studies of cells, including detection of protein conformation in living cells [16], chemical differences at different stages of the cell cycle $[17,18]$, differences between cells of different phenotypes [19,20] or apoptotic cells [21]. Raman spectroscopy can probe molecular information from living cells revealing distinct chemical features between nucleus and cytoplasm [15,22-24], lipid structures inside cytoplasm [25], and cell response to diverse stress stimuli [26,27]. High resolution Raman imaging provided new insights into the spatial distribution of chemical species and organelles inside cells [28-34]. RMS was used to follow the cellular uptake of the drugs [35-38] and cellular dynamics [39]. Apoptosis, also known as programmed cell death, is an important biological phenomenon that involves morphological and chemical changes of the cell organelles. Raman spectral mapping of apoptotic cells showed changes in the distribution of the nucleic acids $[40,41]$ and detected the accumulation of lipids when cells were treated with different apoptotic drugs [35,42-44].

Nevertheless, one of the most important features of the Raman spectroscopy is the ability to measure time-course molecular changes in live cells, revealing biochemical processes not attainable with other imaging methods [43-47]. Such experiments are of particular relevance to regenerative medicine and tissue engineering applications as repeated Raman measurements can provide time- and spatially-resolved information regarding the molecular properties of stem cells during differentiation or the growth and development of the engineered grafts. Such information may be used for better understanding the biological processes as well as for improving the bioprocesses.

Raman spectroscopy was also used to study molecular changes at the early stages of differentiation of stem cells [48] and for phenotypic identification of stem cell progeny. The differentiation process describes a series of biochemical changes that are meant to transform a stem cell into a fully functional somatic cell. These changes can be correlated to changes in the Raman spectra of cells measured without using labels or affecting their viability [49]. Recent studies have shown that Raman spectral markers can be used to discriminate fully committed mature cells from undifferentiated cells $[23,24,50]$ and to assess the differentiation status of murine stem cells [51]. In addition, RMS may be used for quality control of cell and tissue grafts prior to clinical use. Recent reports discussed the potential of RMS as a non-invasive method for enrichment of cardiomyocyte populations obtained by differentiation of human stem cells [52]. In this mini- 
review paper we present three applications of RMS for time- and spatially-resolved molecular characterisation of stem cells during in-vitro differentiation.

\section{Instrumentation}

Raman micro-spectroscopy is based on coupling a Raman spectrometer to an optical microscope (Figure 1). Inverted optical microscopes are in particular suitable for time-course cell imaging as the cells can be cultured in dedicated enclosed cell-chambers that allow efficient collection of the Raman scattered light while maintaining the cells in culture media and avoiding bacterial contamination. The instrument used for the applications described in this paper was based on an inverted microscope (IX 71, Olympus, Essex, UK) equipped with an environmental enclosure (Solent, Segensworth, UK) that maintains the live cells at $37^{\circ} \mathrm{C}$ and $5 \% \mathrm{CO}_{2}$ atmosphere. A water immersion microscope objective (Olympus) $60 \times / 1.2$ N.A. was used to focus the $785 \mathrm{~nm}$ laser beam (Toptica Xtra) and collect the Raman scattered light, which was then analysed by an optical spectrometer (830nm diffraction grating, IDus 401 CCD, Andor Technologies, Belfast, UK). The spectrometer was connected to the microscope through a $50 \mu \mathrm{m}$ diameter optical fibre, providing a spectral resolution of $\sim 4 \mathrm{~cm}^{-1}$. A step motorize stage (Prior, Cambridge, UK) was attached to the microscope to raster scan the sample area. The microscope also had an integrated wide-field fluorescence imaging system that allowed imaging of the cells at the end of the Raman spectral measurements, after staining with specific labelles. For typical experiments for cell imaging, the laser power at the sample was in the 100-150 mW range and the exposure time per spot 0.5-2 s (total time required for the aquisiot of a Raman image of a cell $\sim 20-40$ minutes at $1 \mu \mathrm{m}$ step-size).

\section{Applications}

Assessment of differentiation status of neuro-progenitor stem cells

Neural stem cells are responsible for the generation of neurons and glial cells and offer great promise to develop treatments for Parkinson's, Alzheimer's diseases, chronic inflammatory disorders of the central nervous system, spinal cord injuries or strokes

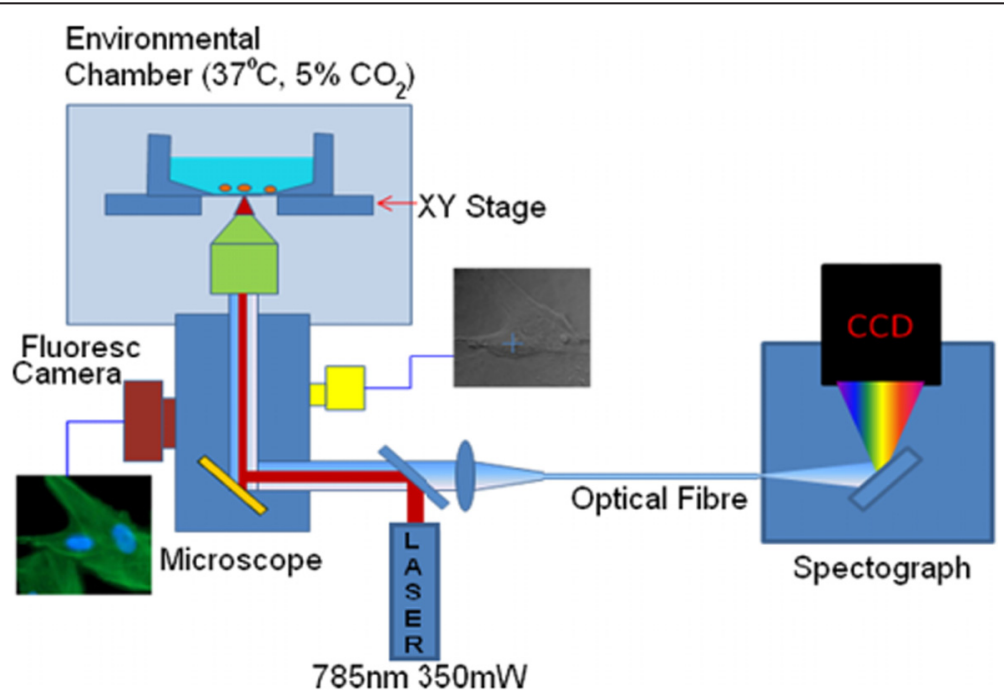

Figure 1 Schematic description of a Raman micro-spectrometer suitable for monitoring time- and spatially-resolved molecular changes in live stem cells. 
[53]. The capacity of endogenous neural stem cells to proliferate and replace neural cells in-vivo may be affected by chronic inflammatory processes [53]. Hence the repair potential of endogenous stem cells may be limited and any medical procedures designed to mobilize neural stem towards inflammatory sites may be limited. Thus, therapies based on transplantation of neural stem cells from exogenous sources have been developed recently [54].

Raman micro-spectroscopy was proposed as a label-free method for identification of neural stem cells and discrimination of glial cells. Raman spectra of neuro-progenitor cells and glial cells showed significant differences in the fingerprint spectral region $\left(600-1800 \mathrm{~cm}^{-1}\right)$ (Figure 2A,B). A multivariate statistical model was developed that allowed discrimination between neural stem cells and glial cells with $89.4 \%$ sensitivity and $96.4 \%$ specificity [55]. The computed difference between the average Raman spectra of neuro-progenitor and glial cells shows a close similarity with the Raman spectrum of purified RNA (Figure 2B).

Focusing on the $700-830 \mathrm{~cm}^{-1}$ region, distinct spectral signatures from nucleic acid base pairs can be observed: adenine $\left(729 \mathrm{~cm}^{-1}\right)$, uracil and cytosine $\left(782 \mathrm{~cm}^{-1}\right.$ and $\left.785 \mathrm{~cm}^{-1}\right)$. Raman bands corresponding to the stretching vibrations of phosphate O-P-O backbone of nucleic acids can also be identified: $788 \mathrm{~cm}^{-1}$ for B-DNA, and $788 \mathrm{~cm}^{-1}$ and $813 \mathrm{~cm}^{-1}$ for RNA [56]. Raman spectra measured at different locations inside live neuro-progenitor stem cells indicate that regions rich in RNA are found mostly in the cytoplasms of these cells (Figure 2E, F).

Raman micro-spectroscopy can measure detailed molecular maps of cells to obtain spatially-resolved chemical information inside the cells with spatial resolution down to

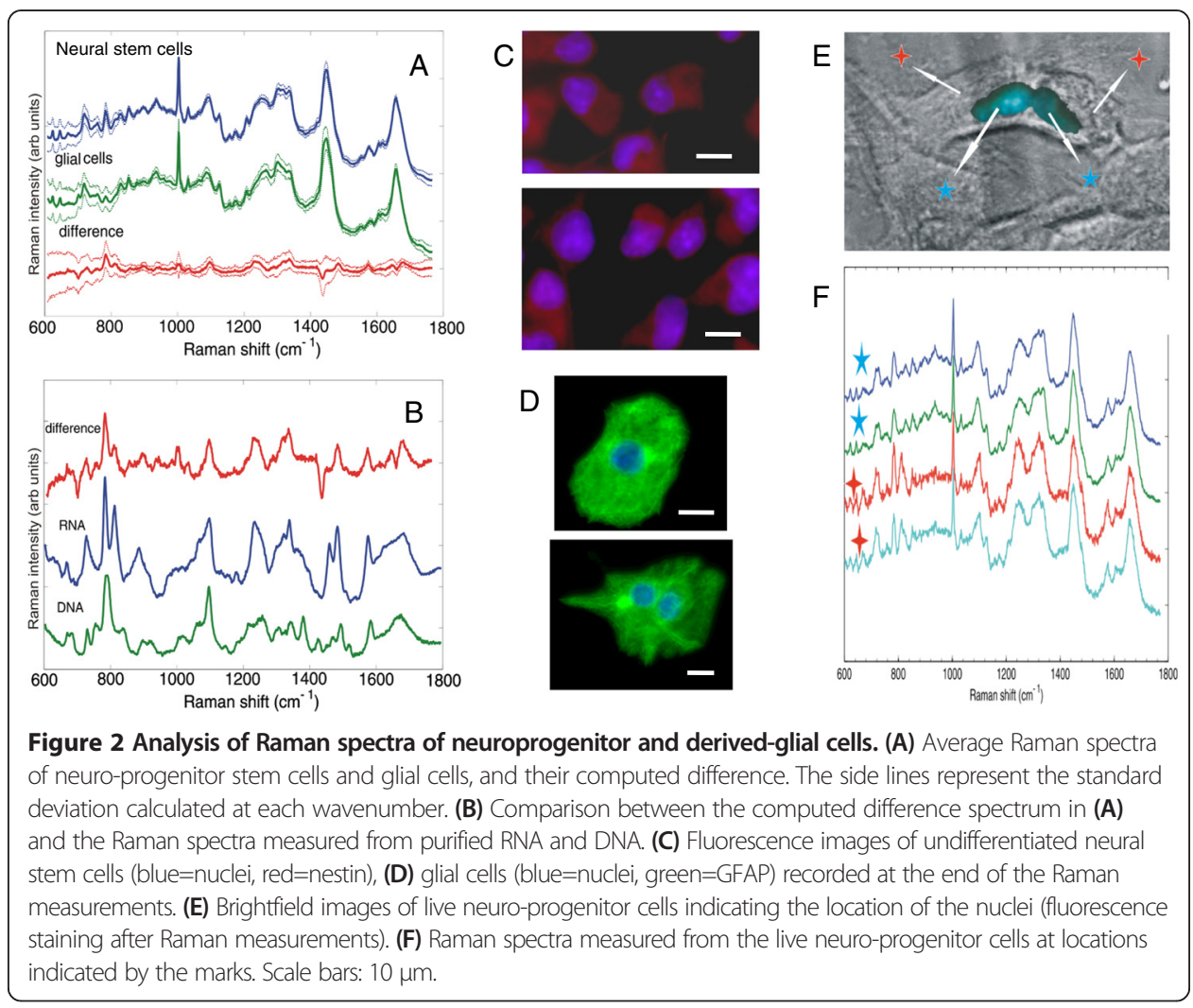


the diffraction limit $(\sim 750 \mathrm{~nm}$ in this case). Figure 3 presents Raman spectral maps along with fluorescence and phase contrast images of neuro-progenitor and glial cells. The Raman maps presented in Figure 3 were constructed by computing the peak area of the $788 \mathrm{~cm}^{-1}$ and $813 \mathrm{~cm}^{-1}$ bands for each Raman spectrum after subtracting the local baseline. The cells were raster scanned with a step size of $500 \mathrm{~nm}$.

For neuro-progenitor cells (Figure 3), the Raman maps corresponding to the $788 \mathrm{~cm}^{-1}$ band is slightly larger than the DAPI staining of the cell nucleus as it contains spectral overlap signature from DNA and RNA. On the other hand, the band at $813 \mathrm{~cm}^{-1}$, specifically assigned to RNA, reveals high amount of RNA in the cytoplasm. However, Raman maps recorded for glial cells (Figure $3 \mathrm{H}$ ) fail to detect bands corresponding to RNA in the cytoplasm. By developing a solution-based calibration model for RNA, the maximum concentration of RNA in the cytoplasm of neuro-progenitor stem cells ranged from 3-5 mg/ml (accuracy in this range is $\pm 0.4 \mathrm{mg} / \mathrm{ml}$ ) while for glial cells the concentration becomes lower than the detection limit of RNA for our instrument, which is $\sim 1 \mathrm{mg} / \mathrm{ml}$

This finding was somehow surprising considering that the ribosomal RNA represents the dominant type of RNA in cells and most somatic cells have abundant ribosomes. However, the estimates of the cell volumes indicate that the increase in the cytoplasm volume for glial cells by a factor of 4.5 may account for a decrease in the cytoplasm RNA concentration during the differentiation of neuroprogenitor cells to the glial phenotype. The higher intensities of Raman bands corresponding to RNA in neural stem cells may also be related to a higher amount of RNA in the cytoplasm of undifferentiated cells as suggested by earlier histological analysis of embryonic brain explants. These studies showed that neuroepithelial progenitor populations in the ependymal layer have a higher total RNA content than their mature differentiated progeny [57]. Increased concentration of non-translated mRNAs corresponding to the posttranscriptional control of genes has been related to neurogenesis [58], neuronal function [59], as well as stem cell proliferation and embryogenesis [60,61]. For example, high abundance of proteins which repress the translation of mRNAs and maintained the undifferentiated state of neuroprogenitor stem cells have been found in the

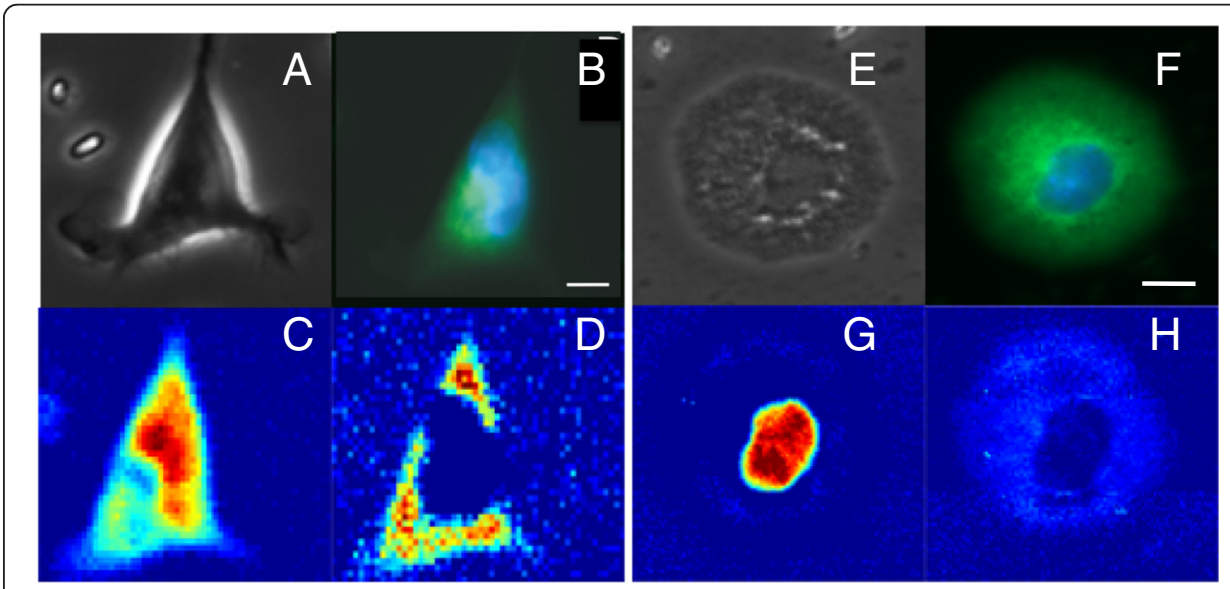

Figure 3 Raman spectral imaging of neuroprogenitor and derived-glial cells. Phase contrast images $(\mathbf{A}, \mathbf{E}), \mathrm{DAPI}$ (blue)/FITC (green) fluorescence staining $(\mathbf{B}, \mathbf{F})$ and Raman spectral images corresponding to the $788 \mathrm{~cm}^{-1}$ band $(\mathbf{C}, \mathbf{G})$ and $813 \mathrm{~cm}^{-1}$ band $(\mathbf{D}, \mathbf{H})$ for typical fixed neuroprogenitor and glial cells respectively. (Scale bars: $10 \mu \mathrm{m}$ ). 
cytoplasms of these cells [58]. Nevertheless, RMS has the ability to detect and quantify the concentration of RNA in neuroprogenitor cells, with high spatial (less than 1 micron) and temporal resolution (minutes).

Time- and spatially-resolved monitoring of mineralisation of bone nodules in-vitro

Bone is one of the largest organs in the human body with numerous mechanical and haematological functions. In addition to age-related diseases, there are congenital bone deformation, bone cancer and bone trauma that may require a bone transplant. Current bone reconstruction and replacement surgical procedures are based on allogeneic tissue grafts. Because of a limited supply of allogeneic bone, tissue engineering and regeneration of the bone based on mesenchymal stem cells has raised a major research interest. The bone grafts obtained in-vitro can be used for clinical applications to restore the functionality of the skeletal system of the patients [1]. The growth of bone in-vitro requires a culture of mesenchymal stem cells (MSCs) in the osteogenic culture medium. Following proliferation and differentiation, MSCs gives rise to the osteoblasts, which are specialized cells responsible for the formation of the bone nodules. Changes during formation and mineralisation of bone nodules can be observed in Raman bands associated to vibrations of hydroxyapatite, mostly in the $950-960 \mathrm{~cm}^{-1}$ range [29,30]. RMS was used to record time- and spatially-resolved molecular information during differecntiation of MSCs and formation of bone nodules over 28 days time period.

Figure 4 presents phase contrast images of MSCs grown in osteogenic and nonosteogenic media at different time-points. Mineralisation of the cultures grown in osteogenic media was confirmed by alizarin red staining performed at the end of the experiments. The difference between Raman spectra of MSCs grown in osteogenic and non-osteogenic media are presented in Figure 5A. Mineralisation of bone nodules is indicated by the strong Raman band at $\sim 959 \mathrm{~cm}^{-1}$ corresponding to the $\mathrm{PO}_{3}^{-}$symmetric stretching vibrations.

Principal component analysis (PCA) was used to extract temporal and spatial chemical information during differentiation of MSCs. The first four principal components (PCs) containing $99 \%$ from the total variance are presented in the Figure 5B. The loading of $\mathrm{PC} 2$ resembles the Raman spectrum of hydroxyapatite (HA) [62], which containes a sharp peak at $958 \mathrm{~cm}^{-1}$ assigned to $\mathrm{PO}_{3}^{-}$symmetric stretching and represents a strong indication of mineralization. Images obtained by plotting the $\mathrm{PC} 2$ scores provides information regarding the phase (disordered and crystalline) and spatial distribution of HA. Crystalline HA elicits a sharp Raman band at $958 \mathrm{~cm}^{-1}$ while the disordered HA phase is indicated by a broader band in the $940-945 \mathrm{~cm}^{-1}$ region. The intensity peak ratio $\mathrm{I}_{958} / \mathrm{I}_{945}$ represents a strong indicator of spatial and temporal evolution of the HA phase (Figure $5 \mathrm{C}$ ). This ratio was found to increase over time, indicating a higher concentration of disordered phase at the beginning of bone nodule formation leading to a phase transition towards crystalline phase at day 19.

\section{Monitoring cardiac differentiation of human embryonic stem cells}

The human heart is considered to be a non-regenerative tissue and the permanent loss of cardiomyocytes can lead to cardiac muscle failure. For this reason stem cell therapy is considered a desirable alternative to classical heart transplants for replacing the damaged cardiac tissue. Although these technologies offer great promise for patient with cardiac failure, in-vitro differentiation protocols are not optimised and currently produce cell 


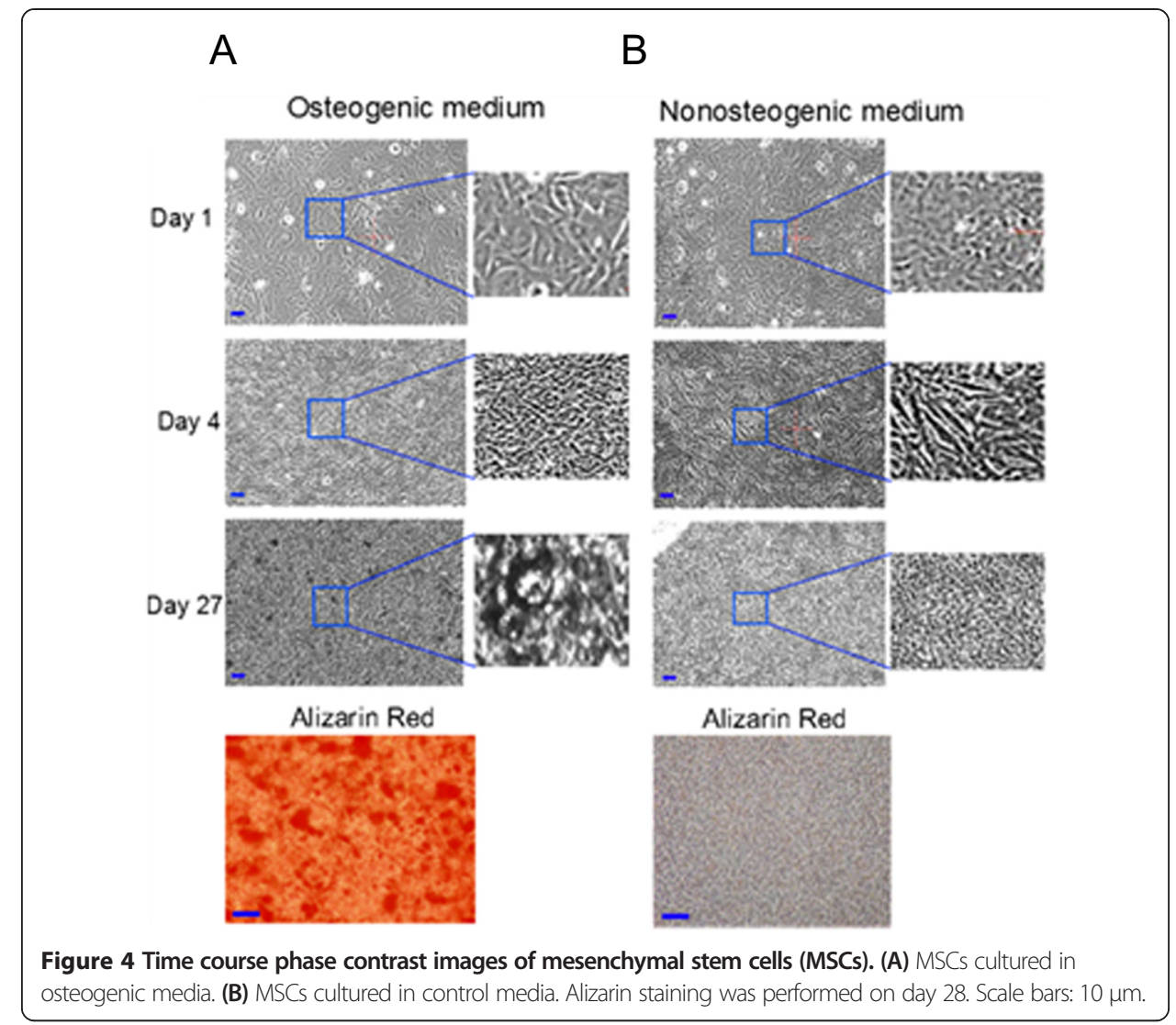

populations with high phenotypic heterogeneity. Such cell populations require further enrichment and purification prior to clinical use [63].

Pascut et. al. showed that RMS can be used for label-free discrimination of individual live cardiomyocytes (CM), derived in-vitro from human embryonic stem cells [64] and investigated the potential for developing Raman-activated cell-sorting of individual cells [52]. A statistical multivariate model using principal component analysis of Raman spectra from stem cell-derived CMs and non-CMs achieved 97\% specificity and 96\% sensitivity [64]. It was found that the main spectral features that provided the discrimination were related to Raman bands associated to glycogen and proteins [28]. Furthermore, online analysis of the beat frequency of individual cardiomyocytes analysed by RMS showed no significant differences when exposed to the Raman laser, when compared to control cells. In a recent study, RMS was used to monitor the molecular changes in live stem cells during cardiac differentiation, and then to correlate these changes to gold-standard fluorescence staining for the cardiac phenotype [65].

Figure 6A presents schematically the design of the experiment in which embryoid bodies (EB) formed by aggregation of human embryonic were grown in conditioned medium on the Raman microscope. The live EBs were grown in conditioned medium to induce differentiation towards cardiac phenotype. Raman spectral maps were acquired by raster-scanning at 24 hour intervals between days 5 and 9 of differentiation, a window wherein cardiac markers were expected to be expressed (immuno-fluorescence on fixed EBs). Flow cytometry and immuno-fluorescence analysis using the CM markers $\alpha$-actinin and/or cardiac troponin I carried out on individual cells dispersed 

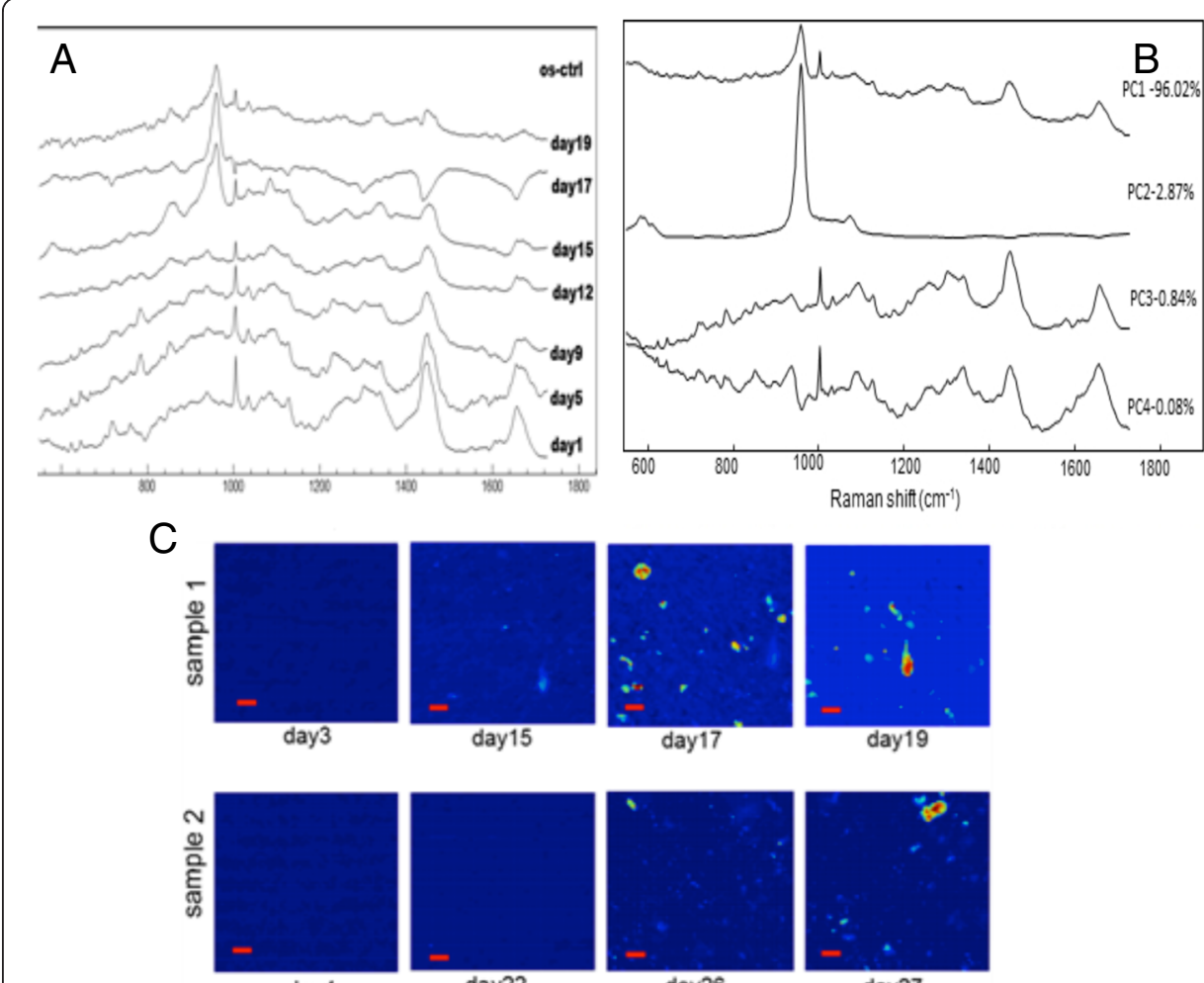

day 22

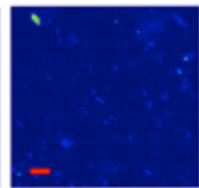

day 26

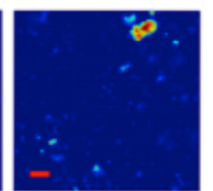

day 27

Figure 5 Time-course Raman spectroscopy of MSC grown in osteogenic medium. (A) Mean time-course Raman spectra of typical $210 \times 210 \mathrm{~mm}^{2}$ regions of the cultures shown in C. Raman spectra were acquired at different time points for the same regions of the culture osteoblast in osteogenic medium and non-osteogenic medium. (B) Principal components used to extract meaningful chemical information (C) Maps corresponding to the PC2 scores recorded in the same culture regions at different measurements days. Scale bar: $10 \mu \mathrm{m}$.

from EBs at day 12 of differentiation indicated that approximately $85 \%$ of the cells present in beating EBs were CMs, whereas less than 1\% were identified as CM in nonbeating EBs.

Figure 7 compares the time-course average Raman spectra of typical EBs, beating (successful cardiac differentiation) and non-beating (unsuccessful cardiac differentiation) with the Raman spectra of individual hESC-derived CMs and a non-CM. Significant differences between the Raman spectra of EBs can be observed starting on day 7, when the spectra of the beating EBs showed an increase in the intensity of the bands at $482 \mathrm{~cm}^{-1}, 577 \mathrm{~cm}^{-1}, 858 \mathrm{~cm}^{-1}, 937 \mathrm{~cm}^{-1}, 1083 \mathrm{~cm}^{-1}$ and $1340 \mathrm{~cm}^{-1}$. The increase in the intensity of these bands was directly correlated with the increase in the number of CMs, and intense bands at the same frequencies can be observed in the Raman spectra of isolated beating CMs derived from hESCs (Figure 7A). These spectral changes were attributed to the formation of myofibrils and accumulation of glycogen in the CMs. These molecular changes are hallmarks for the formation of cardiac tissue and reflect the development of the contractile machinery of the CMs [66,67]. A high accumulation of glycogen in hESC-derived CMs was observed by transmission electron microscopy for CMs derived from several hESCs lines [67] and was related to the increase in fuel demand following the switch from the glycolytic metabolism to oxidative phosphorylaion $[68,69]$. 


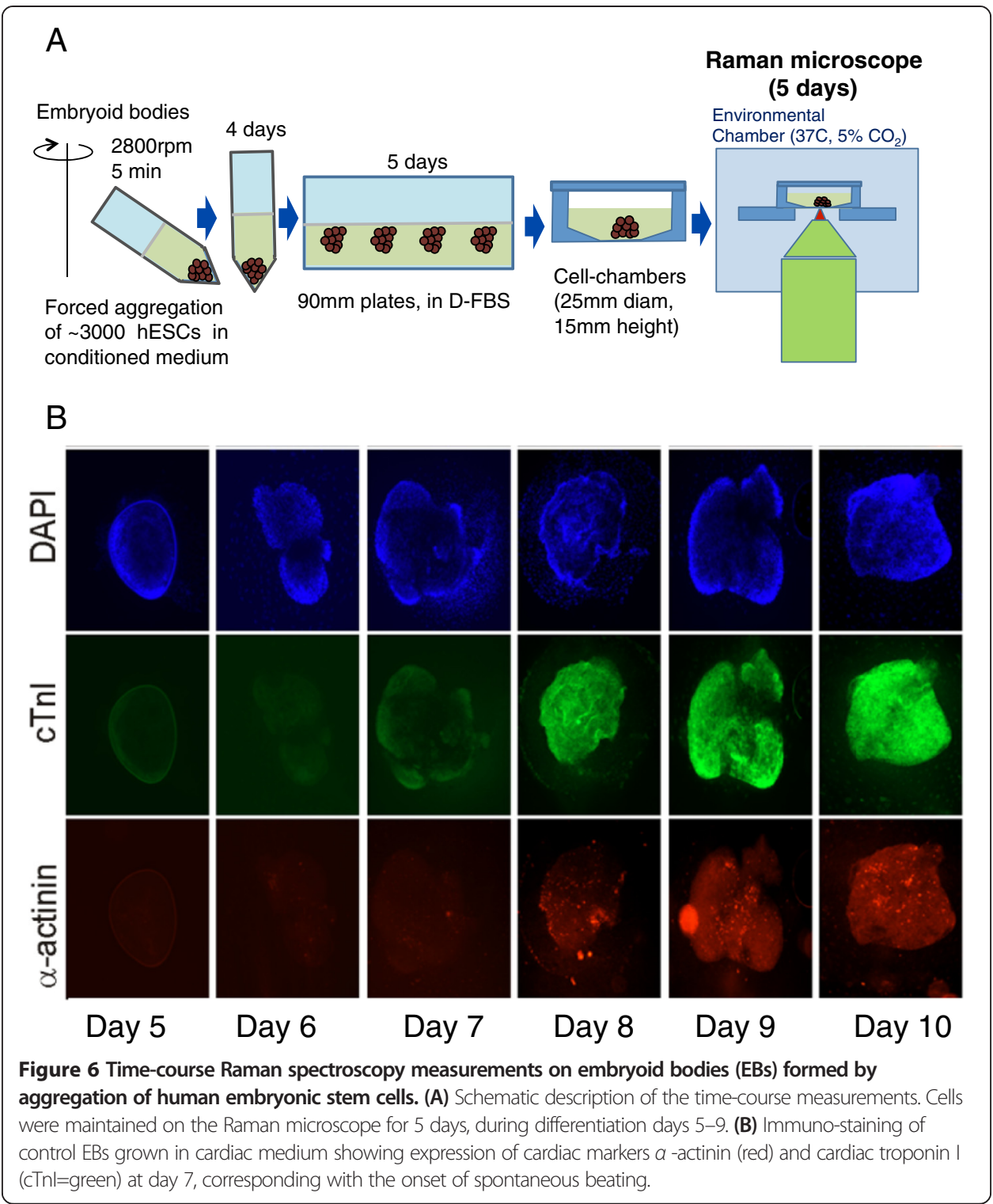

RMS can also provide time-resolved 2D spectral maps of the EBs and is able to detect the increase in the number of CMs during differentiation. Starting with day 7, the spectral maps show the appearance of CMs in the beating EBs, while no relative increase in the $\mathrm{PC} 1$ scores was detected in the non-beating EBs. It was also found that the areas of high PC1 scores also matched the regions of the EBs where the beating was most pronounced, as well as the expression of $\alpha$-actinin obtained by immuno-fluorescence imaging at the end of the time-course experiments [65]. These recent studies show the potential of RMS for non-invasive monitoring of stem cell differentiation, which may enable a more efficient optimization of the relevant bioprocesses.

\section{Conclusion}

This paper reviews recent applications of Raman micro-spectroscopy for time- and spatially-resolved molecular imaging of stem cells during differentiation in-vitro. By 


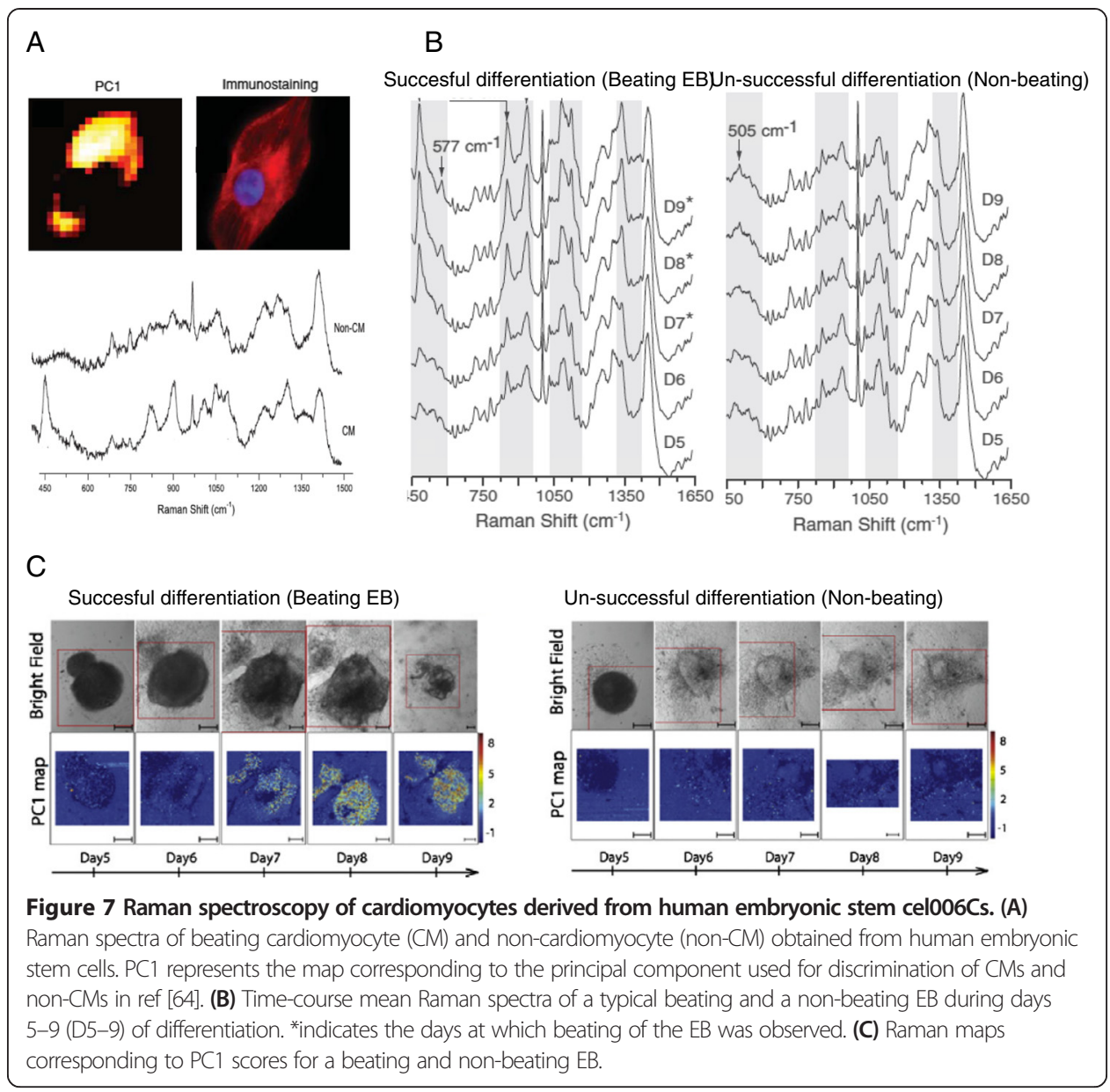

integrating the Raman micro-spectrometer with an environmental enclosure, RMS can be used for non-invasive monitoring time-dependent molecular changes in live cells and can provide on-line information regarding the cells and their phenotypic characteristics. RMS may be a useful technique for monitoring bioprocesses and help the refinement and standardisation of differentiation protocols to induce the efficient differentiation of pluripotent stem cells. Such non-invasive techniques are needed to help overcoming the current bottlenecks in the manufacturing and quality assessment of stem cell populations, which are key factors for the future advancement and widespread clinical use of regenerative medicine therapies. In addition, information regarding molecular changes during differentiation can advance the understanding of stem cell differentiation and the development of in vitro models for embryo development. RMS can also provide an invaluable platform for further fundamental studies on stem cells and the effect of various stimuli on their differentiation (eg. mechanical stimulation for osteoblasts), as well as in-vitro testing of new pharmaceuticals on cell models.

Competing interests

The authors declare that they have no competing interests.

Authors' contributions

AG carried out the Raman spectroscopy experiments on neuroprogenitor and mesenchymal stem cells, and drafted the paper. FCP carried out the Raman spectroscopy on hESCS ad cardiomyocytes. VS and CD conceived the study and supervised the cell-cultures. IN conceived the study, supervised the Raman spectroscopy measurements and drafted the paper. All authors read and approved the paper. 


\section{Acknowledgements}

This work was supported by the Biotechnology and Biological Sciences Research Council, UK (BB/G010285/1).

\section{Author details}

${ }^{1}$ School of Physics and Astronomy, University of Nottingham, Nottingham NG7 2RD, UK. ${ }^{2}$ School of Medicine, University of Nottingham, Nottingham NG7 2RD, UK.

Received: 24 October 2014 Accepted: 5 March 2015

Published online: 24 March 2015

\section{References}

1. Frohlich M, Grayson WL, Wan LQ, Marolt D, Drobnic M, Vunjak-Novakovic G. Tissue engineered bone grafts: biological requirements, tissue culture and clinical relevance. Curr Stem Cell Res Ther. 2008;3:254-64.

2. Williams D. Benefit and risk in tissue engineering. Mater Today. 2004;7:24-9.

3. Evans MJ, Kaufman MH. Establishment in culture of pluripotential cells from mouse embryos. Nat. 1981;292:154-6.

4. Dean M. Cancer stem cells: redefining the paradigm of cancer treatment strategies. Mol Interv. 2006;6:140-8.

5. Choumerianou DM, Dimitriou H, Kalmanti M. Stem cells: promises versus limitations. Tissue Eng Part B Rev. 2008;14:53-60

6. Trouillon R, Passarelli MK, Wang J, Kurczy ME, Ewing AG. Chemical analysis of single cells. Anal Chem. 2013;85:522-42.

7. Lin Y, Trouillon R, Safina G, Ewing AG. Chemical analysis of single cells. Anal Chem. 2011;83:4369-92.

8. Bour-Dill C, Gramain MP, Merlin JL, Marchal S, Guillemin F. Determination of intracellular organelles implicated in daunorubicin cytoplasmic sequestration in multidrug-resistant MCF-7 cells using fluorescence microscopy image analysis. Cytometry. 2000;39:16-25.

9. Rusan NM, Fagerstrom CJ, Yvon AMC, Wadsworth P. Cell cycle-dependent changes in microtubule dynamics in living cells expressing green fluorescent protein-alpha tubulin. Mol Biol Cell. 2001;12:971-80.

10. Caspers PJ, Lucassen GW, Carter EA, Bruining HA, Puppels GJ. In vivo confocal Raman microspectroscopy of the skin: noninvasive determination of molecular concentration profiles. J Invest Dermatol. 2001;116:434-42.

11. Meyer T, Bergner N, Bielecki C, Krafft C, Akimov D, Romeike BF, et al. Nonlinear microscopy, infrared, and Raman microspectroscopy for brain tumor analysis. J Biomed Opt. 2011;16:021113.

12. Kendall C, Stone N, Shepherd N, Geboes K, Warren B, Bennett R, et al. Raman spectroscopy, a potential tool for the objective identification and classification of neoplasia in Barrett's oesophagus. J Pathol. 2003;200:602-9.

13. Kong K, Rowlands CJ, Varma S, Perkins W, Leach IH, Koloydenko AA, et al. Diagnosis of tumors during tissueconserving surgery with integrated autofluorescence and Raman scattering microscopy. Proc Natl Acad Sci U S A. 2013;110:15189-94.

14. Delhaye M, Dhamelincourt P. Raman microprobe and microscope with laser excitation. J Raman Spectrosc. 1975;3:33-43.

15. Puppels GJ, Demul FFM, Otto C, Greve J, Robertnicoud M, Arndtjovin DJ, et al. Studying single living cells and chromosomes by confocal Raman microspectroscopy. Nat. 1990;347:301-3.

16. Ye J, Fox SA, Cudic M, Rezler EM, Lauer JL, Fields GB, et al. Determination of penetratin secondary structure in live cells with Raman microscopy. J Am Chem Soc. 2010;132:980-8.

17. Matthews Q, Jirasek A, Lum J, Duan XB, Brolo AG. Variability in Raman spectra of single human tumor cells cultured in vitro: correlation with cell cycle and culture confluency. Appl Spectrosc. 2010;64:871-87.

18. Swain RJ, Jell G, Stevens MA. Non-invasive analysis of cell cycle dynamics in single living cells with Raman micro-spectroscopy. J Cell Biochem. 2008;104:1427-38.

19. Notingher I, Jell G, Lohbauer U, Salih V, Hench LL. In situ non-invasive spectral discrimination between bone cell phenotypes used in tissue engineering. J Cell Biochem. 2004;92:1180-92.

20. Brown KL, Palyvoda OY, Thakur JS, Nehlsen-Cannarella SL, Fagoaga OR, Gruber SA, et al. Raman spectroscopic differentiation of activated versus non-activated T lymphocytes: an in vitro study of an acute allograft rejection model. J Immunol Methods. 2009;340:48-54.

21. Notingher I, Verrier S, Haque S, Polak JM, Hench LL. Spectroscopic study of human lung epithelial cells (A549) in culture: living cells versus dead cells. Biopolymers. 2003;72:230-40.

22. Draux F, Gobinet C, Sule-Suso J, Manfait M, Jeannesson P, Sockalingum GD. Raman imaging of single living cells: probing effects of non-cytotoxic doses of an anti-cancer drug. Analyst (Cambridge, U K). 2011;136:2718-25.

23. Hedegaard M, Krafft C, Ditzel HJ, Johansen LE, Hassing S, Popp J. discriminating isogenic cancer cells and identifying altered unsaturated fatty acid content as associated with metastasis status, using k-means clustering and partial least squares-discriminant analysis of Raman maps. Anal Chem. 2010;82:2797-802.

24. Nawaz H, Bonnier F, Meade AD, Lyng FM, Byrne HJ. Comparison of subcellular responses for the evaluation and prediction of the chemotherapeutic response to cisplatin in lung adenocarcinoma using Raman spectroscopy. Analyst (Cambridge, U K). 2011;136:2450-63.

25. Pully W, Lenferink A, Otto C. Hybrid Rayleigh, Raman and two-photon excited fluorescence spectral confocal, microscopy of living cells. J Raman Spectrosc. 2010;41:599-608.

26. Konorov SO, Jardon MA, Piret JM, Blades MW, Turner RFB. Raman microspectroscopy of live cells under autophagy-inducing conditions. Analyst (Cambridge, U K). 2012;137:4662-8.

27. Hosoda A, Maruyama A, Oikawa D, Oshima Y, Komachi Y, Kanai G, et al. Detection of ER stress in vivo by Raman spectroscopy. Biochem Biophys Res Commun. 2011;405:37-41.

28. Konorov SO, Schulze HG, Piret JM, Turner RFB, Blades MW. Evidence of marked glycogen variations in the characteristic Raman signatures of human embryonic stem cells. J Raman Spectrosc. 2011;42:1135-41.

29. McManus LL, Burke GA, McCafferty MM, O'Hare P, Modreanu M, Boyd AR, et al. Raman spectroscopic monitoring of the osteogenic differentiation of human mesenchymal stem cells. Analyst (Cambridge, U K). 2011;136:2471-81.

30. McManus LL, Bonnier F, Burke GA, Meenan BJ, Boyd AR, Byrne HJ. Assessment of an osteoblast-like cell line as a model for human primary osteoblasts using Raman spectroscopy. Analyst (Cambridge, U K). 2012;137:1559-69. 
31. Gentleman E, Swain RJ, Evans ND, Boonrungsiman S, Jell G, Ball MD, et al. Comparative materials differences revealed in engineered bone as a function of cell-specific differentiation. Nat Mater. 2009;8:763-70.

32. van Manen HJ, Kraan YM, Roos D, Otto C. Single-cell Raman and fluorescence microscopy reveal the association of lipid bodies with phagosomes in leukocytes. Proc Natl Acad Sci U S A. 2005;102:10159-64.

33. Krafft C, Knetschke T, Funk RHW, Salzer R. Identification of organelles and vesicles in single cells by Raman microspectroscopic mapping. Vib Spectrosc. 2005;38:85-93.

34. Uzunbajakava N, Lenferink A, Kraan Y, Willekens B, Vrensen G, Greve J, et al. Nonresonant Raman imaging of protein distribution in single human cells. Biopolymers. 2003;72:1-9.

35. Uzunbajakava N, Lenferink A, Kraan Y, Volokhina E, Vrensen G, Greve J, et al. Nonresonant confocal Raman imaging of DNA and protein distribution in apoptotic cells. Biophys J. 2003;84:3968-81.

36. Matthaus C, Chernenko T, Newmark JA, Warner CM, Diem M. Label-free detection of mitochondrial distribution in cells by nonresonant Raman microspectroscopy. Biophys J. 2007;93:668-73.

37. Draux F, Jeannesson P, Beljebbar A, Tfayli A, Fourre N, Manfait M, et al. Raman spectral imaging of single living cancer cells: a preliminary study. Analyst (Cambridge, U K). 2009;134:542-8.

38. Miljkovic M, Chernenko T, Romeo MJ, Bird B, Matthaus C, Diem M. Label-free imaging of human cells: algorithms for image reconstruction of Raman hyperspectral datasets. Analyst (Cambridge, U K). 2010;135:2002-13.

39. Chernenko T, Matthaus C, Milane L, Quintero L, Amiji M, Diem M. Label-free Raman spectral imaging of intracellular delivery and degradation of polymeric nanoparticle systems. ACS Nano. 2009;3:3552-9.

40. Ling J, Weitman SD, Miller MA, Moore RV, Bovik AC. Direct Raman imaging techniques for study of the subcellular distribution of a drug. Appl Optics. 2002;41:6006-17.

41. Meister K, Niesel J, Schatzschneider U, Metzler-Nolte N, Schmidt DA, Havenith M. Label-free imaging of metal-carbonyl complexes in live cells by Raman microspectroscopy. Angew Chem Int Ed. 2010;49:3310-2.

42. Fukunaga H, Yoshimura H, Nishina Y, Nagashima Y, Tachibana M. Label-free biomedical imaging of hydrodynamics in single human cells. Biomed Res-Tokyo. 2010;31:177-81.

43. Huang YS, Karashima T, Yamamoto M, Hamaguchi H. Molecular-level investigation of the structure, transformation, and bioactivity of single living fission yeast cells by time- and space-resolved Raman spectroscopy. Biochem. 2005;44:10009-19.

44. Zoladek A, Pascut FC, Patel P, Notingher I. Non-invasive time-course imaging of apoptotic cells by confocal Raman micro-spectroscopy. J Raman Spectrosc. 2011;42:251-8.

45. Eder SH, Gigler AM, Hanzlik M, Winklhofer M. Sub-micrometer-scale mapping of magnetite crystals and sulfur globules in magnetotactic bacteria using confocal Raman micro-spectrometry. PLoS One. 2014;9:e107356.

46. Okada M, Smith NI, Palonpon AF, Endo H, Kawata S, Sodeoka M, et al. Label-free Raman observation of cytochrome c dynamics during apoptosis. Proc Natl Acad Sci U S A. 2012;109:28-32.

47. Venkata HNN, Shigeto S. Stable isotope-labeled Raman imaging reveals dynamic proteome localization to lipid droplets in single fission yeast cells. Chem Biol. 2012;19:1373-80

48. Swain RJ, Kemp SJ, Goldstraw P, Tetley TD, Steyens MM. Assessment of cell line models of primary human cells by Raman spectral phenotyping. Biophys J. 2010;98:1703-11.

49. Chan JW, Taylor DS, Zwerdling T, Lane SM, Ihara K, Huser T. Micro-Raman spectroscopy detects individual neoplastic and normal hematopoietic cells. Biophys J. 2006;90:648-56.

50. Zuser E, Chernenko T, Newmark J, Miljkovic M, Diem M. Confocal Raman microspectral imaging (CRMI) of murine stem cell colonies. Analyst (Cambridge, U K). 2010;135:3030-3.

51. Notingher L, Bisson I, Polak JM, Hench LL. In situ spectroscopic study of nucleic acids in differentiating embryonic stem cells. Vib Spectrosc. 2004;35:199-203.

52. Pascut FC, Goh HT, George V, Denning C, Notingher I. Toward label-free Raman-activated cell sorting of cardiomyocytes derived from human embryonic stem cells. J Biomed Opt. 2011;16:045002.

53. Martino G, Pluchino S. The therapeutic potential of neural stem cells. Nat Rev Neurosci. 2006;7:395-406.

54. Giusto E, Donega M, Cossetti C, Pluchino S. Neuro-immune interactions of neural stem cell transplants: From animal disease models to human trials. Exp Neurol. 2014;260:19-32.

55. Ghita A, Pascut FC, Mather M, Sottile V, Notingher I. Cytoplasmic RNA in undifferentiated neural stem cells: a potential label-free raman spectral marker for assessing the undifferentiated status. Anal Chem. 2012;84:3155-62.

56. Tu AT. Raman spectroscopy in biology: principles and applications. New York: Wiley; 1982.

57. Birge WJ. A histochemical study of ribonucleic acid in differentiating ependymal cells of the chick embryo. Anat Rec. 1962:143:147-55.

58. Okano H, Kawahara H, Toriya M, Nakao K, Shibata S, Imai T. Function of RNA-binding protein Musashi-1 in stem cells. Exp Cell Res. 2005;306:349-56.

59. Finkenstadt PM, Kang WS, Jeon M, Taira E, Tang W, Baraban JM. Somatodendritic localization of Translin, a component of the Translin/Trax RNA binding complex. J Neurochem. 2000;75:1754-62.

60. Kuersten S, Goodwin EB. The power of the 3' UTR: translational control and development. Nat Rev Genet. 2003:4:626-37

61. Macnicol MC, Macnicol AM. Developmental timing of mRNA translation-integration of distinct regulatory elements. Mol Reprod Dev. 2010;77:662-9.

62. Ghita A, Pascut FC, Sottile V, Notingher I. Monitoring the mineralisation of bone nodules in vitro by space- and time-resolved Raman micro-spectroscopy. Analyst (Cambridge, U K). 2014;139:55-8.

63. Musunuru K, Domian IJ, Chien KR. Stem cell models of cardiac development and disease. Annu Rev Cell Dev Biol, Vol 26. 2010;26:667-87.

64. Pascut FC, Goh HT, Welch N, Buttery LD, Denning C, Notingher I. Noninvasive detection and imaging of molecular markers in live cardiomyocytes derived from human embryonic stem cells. Biophys J. 2011;100:251-9.

65. Pascut FC, Kalra S, George V, Welch N, Denning C, Notingher I. Non-invasive label-free monitoring the cardiac differentiation of human embryonic stem cells in-vitro by Raman spectroscopy. Biochim Et Biophys Acta-Gen Subj. 1830;2013:3517-24.

66. Snir M, Kehat I, Gepstein A, Coleman R, Itskovitz-Eldor J, Livne E, et al. Assessment of the ultrastructural and proliferative properties of human embry- onic stem cell-derived cardiomyocytes. Am J Physiol Heart Circ Physiol. 2003;285:H2355-63. 
67. Gherghiceanu M, Barad L, Novak A, Reiter I, Itskovitz-Eldor J, Binah O, et al. Cardiomyocytes derived from human embryonic and induced pluripotent stem cells: comparative ultrastructure. J Cell Mol Med. 2011;15:2539-51.

68. St John JC, Ramalho-Santos J, Gray HL, Petrosko P, Rawe VY, Navara CS, et al. The expression of mitochondrial DNA transcription factors during early cardiomyocyte in vitro differentiation from human embryonic stem cells. Cloning Stem Cells. 2005;7:141-53

69. Chung S, Dzeja PP, Faustino RS, Perez-Terzic C, Behfar A, Terzic A. Mitochondrial oxidative metabolism is required for the cardiac differentiation of stem cells. Nat Clin Pract Cardiovasc Med. 2007;4:560-7.

Submit your manuscript to a SpringerOpen ${ }^{\circ}$ journal and benefit from:

- Convenient online submission

- Rigorous peer review

- Immediate publication on acceptance

- Open access: articles freely available online

- High visibility within the field

- Retaining the copyright to your article

Submit your next manuscript at $>$ springeropen.com 